\title{
Pegada de carbono do ciclo de vida da Celulose de eucalipto: estudo DE CASO NUMA EMPRESA BAIANA
}

\author{
Carina de Farias Gonçalves ${ }^{1 *}$, Solange Rodrigues Santos Correa², Luciano Brito Rodrigues ${ }^{3}$, José Adolfo
}

\author{
Almeida Neto ${ }^{4}$
}

\author{
${ }^{1}$ Programa de Pós-Graduação em Desenvolvimento e Meio Ambiente (PRODEMA), Universidade Estadual de Santa Cruz. (UESC) \\ ${ }^{2}$ Departamento de Ciências Administrativas e Contábeis, Universidade Estadual de Santa Cruz. \\ ${ }^{3}$ Departamento de Tecnologia Rural e Animal, Universidade Estadual do Sudoeste da Babia, Campus de Itapetinga \\ ${ }^{4}$ Departamento de Ciências Agrárias e Ambientais, Universidade Estadual de Santa Cruz. \\ *Autorpara correspondência: afgoncalves@uesc.br
}

Recebido em 29 de novembro de 2016. Aceito em 05 de setembro de 2018. Publicado em 28 de dezembro de 2018.

REsumo - Este trabalho avaliou a pegada de carbono no ciclo de vida da celulose de eucalipto produzido numa indústria na Bahia. O estudo considerou a importância ambiental e econômica da produção de celulose para o setor, bem como a crescente demanda na sua utilização pelas indústrias de papel e derivados. O cálculo da pegada de carbono foi realizado com base nos princípios da Avaliação de Ciclo de Vida conforme as normas ISO 14040/44. O estudo quantificou os fluxos de energia e materiais bem como, sua caracterização enquanto emissões de GEE, considerando as etapas de silvicultura, indústria e distribuição da celulose. $\mathrm{O}$ inventário foi construído com dados secundários através de consultas à literatura especializada e banco de dados Ecoinvent 2.2 para a silvicultura e, para as etapas industrial e distribuição através de relatórios anuais da empresa, formulários e planilhas de inventário das entradas e saídas coletados em visitas técnicas à fábrica. A pegada de carbono, calculada com o auxílio do software Umberto foi de $374,77 \mathrm{kgCO}_{2}$-eq/tsa, superior à estimada nos relatórios de sustentabilidade da empresa. O consumo de hidróxido de sódio, dióxido de cloro, magnésio e, principalmente, o uso de combustíveis fósseis foram os inputs com maior contribuição na emissão do ciclo de vida da celulose, sendo este último o principal responsável. O MDL, implantado com base numa abordagem de ciclo de vida, pode contribuir para a melhoria do desempenho na emissão de GEE da celulose.

Palavras-chave: Inventário do Ciclo de Vida; Emissão de gases estufa; Mudanças climáticas.

\section{EUCALYPTUS CELLULOSE LIFE CYCLE CARBON FOOTPRINT: A CASE STUDY IN A BAIANA COMPANY}

ABSTRACT - This work evaluated the carbon footprint in the life cycle of eucalyptus pulp produced in an industry in Bahia. The study considered the environmental and economic importance of the production of pulp for the sector, as well as the growing demand in its use by the pulp and paper industries. The calculation of the carbon footprint was carried out based on the principles of the Life Cycle Assessment according to ISO 14040/44. The study quantified the flows of energy and materials as well as their characterization as GHG emissions, considering the stages of silviculture, industry and pulp distribution. The inventory was constructed with secondary data through queries to specialized literature and database Ecoinvent 2.2 for forestry and, for the industrial stages and distribution through annual reports of the company, forms and worksheets of the inventory of inputs and outputs collected in technical visits to the factory. The carbon footprint, calculated with the aid of software Umberto was 374.77 $\mathrm{kgCO} 2$-eq / tsa, higher than estimated in the company's sustainability reports. The consumption of sodium hydroxide, chlorine dioxide, magnesium and, mainly, the use of fossil fuels were the inputs with greater contribution in the emission of the cellulose life cycle, being the latter the main one responsible. The CDM, implemented on the basis of a life cycle approach, can contribute to the improvement of the performance in the emission of cellulose GHG.

Keywords: Life Cycle Inventory; Greenhouse gases emissions; Climate Changes. 


\section{Huella de CARBono del Ciclo de VIDA de LA CElulosa de EUCALIPTO:ESTUdio De CASO EN UNA EMPRESA BAIANA}

Resumen - Este trabajo evaluó la huella de carbono en el ciclo de vida de la celulosa de eucalipto producida en una industria en Bahía. El estudio consideró la importancia ambiental y económica de la producción de celulosa para el sector, así como la creciente demanda en su uso por las industrias de papel y derivados. El cálculo de la huella de carbono se basó en los principios de la Evaluación del Ciclo de Vida según la norma ISO 14040/44. El estudio cuantificó los flujos de energía y materiales, así como su caracterización como emisiones de GEI, considerando las etapas de silvicultura, industria y distribución de pulpa. El inventario fue construido con datos secundarios a través de consultas a la literatura especializada y a la base de datos Ecoinvent 2.2 para la silvicultura, y para las etapas industrial y de distribución a través de informes anuales de la empresa, formularios y plantillas de inventario de las entradas y salidas recogidos en visitas técnicas a la fábrica. La huella de carbono, calculada utilizando el software Umberto, fue de 374,77 $\mathrm{kgCO} 2$-eq / tsa, superior a la estimada en los informes de sostenibilidad de la empresa. El consumo de hidróxido de sodio, dióxido de cloro, magnesio y, principalmente, el uso de combustibles fósiles fueron los insumos con mayor contribución en la emisión del ciclo de vida de la celulosa, siendo este último el principal responsable. El MDL, implementado sobre la base de un enfoque de ciclo de vida, puede contribuir a mejorar el desempeño de las emisiones de GEI en la pulpa.

Palabras-clave: El Inventario del Ciclo de Vida; Las emisiones de gases de efecto invernadero; Cambios climáticos.

\section{INTRODUÇÃO}

O fenômeno climático de aquecimento global tem sido intensamente discutido a partir da perspectiva de gases de efeito estufa (GEE) decorrentes da atividade humana, enfatizando o crescente consumo de combustíveis fósseis. Especialistas de áreas afins confirmam a correlação entre o aumento das emissões de GEE e as atividades humanas, bem como a acumulação destes gases na atmosfera, resultando no aquecimento global (Silva et al. 2015). Embora esta questão tenha repercussões em todo o mundo, especialmente as causas e consequências do fenômeno, um grupo de cientistas do clima atribui a recente mudança climática a processos naturais do planeta Terra (Lovelook 2010).

Por isso a relevância da investigação científica para encontrar meios de produção de bens e serviços mais adequados local e ambientalmente a fim de mensurar os efeitos das emissões de GEE de um produto.

Soares et al. (2014) comprovou a relevância do setor florestal na economia brasileira, especialmente as florestas plantadas com Pinus (predominante na região Sul do país, com $77 \%$ da produção nacional) e Eucalyptus (regiões Sudeste e Nordeste representam $65 \%$ da produção nacional) em vários estudos científicos. Os autores citam os estudos de Martins et al. (2003), Valverde (2005) e Sousa et al. (2010) como os trabalhos científicos mais recentes sobre o desempenho desse setor e sua contribuição na economia das regiões brasileiras citadas.

Avaliações do desempenho ambiental de setores produtivos com participação significativa na economia são necessidades de senso comum atualmente. Setores como da produção de celulose, relevante para o desenvolvimento nacional devido ao volume de recursos econômicos que influencia é visto, todavia, como prejudicial por causa das transformações sociais e ambientais que causam nas regiões ocupadas.

Logo, análises orientadas para avaliar e mitigar as emissões de GEE ao longo do ciclo de vida da celulose são fundamentais devido a relevância ambiental, social e econômica do setor e a crescente preocupação em tornar produtos e processos ecologicamente menos impactantes.

O trabalho de Garcia e Freire (2014) avaliou a pegada de carbono em painéis de madeira e a influência das diferentes questões metodológicas utilizadas no cálculo do aglomerado CF. Para tanto, eles utilizaram os seguintes documentos de referência: ISO/TS 14067 (ISO, 2013), o GHG Protocol (BSI, 2008), o PAS 2050 (BSI, 2011) e, a Declaração Climática (IEC, 2008). 
Estudos de Avaliação do Ciclo de Vida (ACV) podem ser úteis para categorizar os impactos ambientais na indústria da celulose, sendo uma das principais técnicas para avaliar quantitativamente os impactos ambientais durante o ciclo de vida de produtos (ISO 14040 2006). A abordagem identifica os impactos ambientais mais relevantes e pode apoiar estratégias de decisão para melhorias ambientais em processos e/ou produtos.

Silva et al. (2015) consideram a ACV como uma das principais técnicas para apoiar as iniciativas de produção mais limpa em empresas e para desenvolver metodologias e indicadores de avaliação que auxiliem a tomada de decisão.

Este estudo visou contribuir para a avaliação do desempenho ambiental do setor florestal por meio da avaliação da pegada de carbono no ciclo de vida da celulose do eucalipto um indicador quantitativo utilizado como referência em muitos estudos científicos. O estudo foi realizando em uma empresa localizada no estado da Bahia, Brasil, considerando-se a importância social e econômica da produção de celulose neste estado e a crescente demanda do produto por indústrias de papel e derivados.

\section{Pegada de carbono}

A definição de pegada de carbono surgiu a partir do conceito de "Pegada Ecológica" proposta por Wackernagel (1996), medida em hectares ou hectares globais. Em linhas gerais, a pegada de carbono significa uma determinada quantidade de emissões gasosas relevantes para a mudança climática associada com a produção humana ou atividades de consumo. Segundo Silva et al (2015 p. 228): “a pegada de carbono é uma questão importante quando se analisa os impactos do aquecimento global na fabricação de produtos à base de madeira, devido à absorção de biogênicas $\mathrm{CO}_{2}$ através do mecanismo de fotossíntese".

A forma de mensuração varia entre medir as emissões do dióxido de carbono direto e as emissões de GEE no ciclo de vida completo. A unidade de medida utilizada para a pegada de carbono é o dióxido de carbono equivalente $\left(\mathrm{CO}_{2}\right.$-eq) calculado a partir dos fatores de emissão dos principais gases estufa considerados pelo Painel Intergovernamental de Mudanças Climáticas (BPWG, 2010).

De acordo com Carbon Trust (2006), a pegada de carbono é "uma metodologia para estimar a emissão total de GEE em equivalentes de carbono de um produto, em todo seu ciclo de vida, da extração das matérias-primas utilizadas, dos processos de fabricação e transporte envolvidos, até sua disposição final”.

Os principais gases e respectivas fontes emissoras de gases estufa são: metano $\left(\mathrm{CH}_{4}\right)$, oriundo de aterros sanitários e fazendas de criação de animais, dióxido de carbono $\left(\mathrm{CO}_{2}\right)$, proveniente da queima de combustíveis fósseis e de mudanças no uso da terra (desmatamento); óxido nitroso $\left(\mathrm{N}_{2} \mathrm{O}\right)$, oriundo da aplicação de fertilizantes nitrogenados; hexafluoreto de enxofre $\left(\mathrm{SF}_{6}\right)$ e perfluorcarbonos (PFCs), liberados na fundição do alumínio, fabricação de semicondutores e rede elétrica; e o vapor d'água que aumenta o volume proporcionalmente à elevação da temperatura, tendo como efeito maior o aumento do impacto de todos os outros gases citados (Almeida 2007, Miller Jr., 2008).

De acordo com o último relatório do Intergovernmental Panel on Climate Change (IPCC 2014) é evidente a influência humana sobre o sistema climático terrestre a partir de suas emissões de GEE que, atingiram, recentemente, sua maior marca na história. Segundo o painel, as recentes mudanças climáticas tiveram impactos generalizados sobre a humanidade e os sistemas naturais.

Os especialistas do IPCC reafirmam, resumidamente, que o aquecimento do sistema climático é inequívoco e, desde a década de 1950, muitas das mudanças observadas são sem precedentes ao longo de milênios. Além da atmosfera, o oceano tem aquecido, as quantidades de neve e gelo têm diminuído e o nível do mar tem aumentado. Segundo o relatório, a temperatura sofreu aumento numa média global de $0,85^{\circ} \mathrm{C}$ entre os anos de 1880 e 2012 , sendo os últimos 30 anos, o período mais quente do hemisfério Norte nos últimos 1400 anos (IPCC 2014). 
Pinheiro et al. (2014) realizaram estudos na agricultura portuguesa utilizando a abordagem de unidades de paisagem para avaliar e quantificar o sequestro e estoque de carbono, bem como fontes e sumidouros de carbono, para produzir respostas a tais alterações, além de alternativas de gestão e monitoramento. Em estudo realizado no sudeste brasileiro, Torres et al. (2013) confrontam duas outras metodologias para estimar sequestro e estoque de carbono, incluindo o método abordado pelo IPCC. De acordo com os autores, resultados desta natureza são relevantes para definir estratégias de mitigação das alterações climáticas e no desenvolvimento de mecanismos para o mercado de carbono.

Han et al. (2015 p. 217) afirma que: “em particular, há aumento do interesse público e vários debates estão ocorrendo em relação aos impactos ambientais associados com a fabricação, o consumo, disposição e reuso de produtos que se originam a partir da floresta".

No sentido de contribuir para a mitigação das mudanças climáticas, identificando pontos críticos e quantificando as emissões de GEE em atividades humanas, o estudo de Gonzaléz et al. (2011), calculou a pegada de carbono da celulose de pinus e de eucalipto, produzida por sete empresas chilenas, com base na norma ISO 14040 (2006). Com o inventário de entradas e saídas de energia e materiais do ciclo de vida completo da celulose branqueada (da extração das matérias-primas até o portão da fábrica), os autores encontraram uma pegada de $401 \mathrm{kgCO}$-eq/t celulose produzida.

\section{Ciclo de vida da celulose de eucalipto}

O ciclo de vida do produto compreende, além da sua composição e processamento, toda vida física deste, desde a obtenção matéria-prima (berço), passando por todas etapas de transporte e processamento do produto final, seu uso até sua destinação final (túmulo) (Heiskanen 2002). Este conceito pode ser aplicado na evolução dos indicadores de sustentabilidade da empresa, por meio da melhoria do desempenho ambiental dos seus produtos e processos (Setac 2009).

O ciclo de vida da celulose, a partir de florestas plantadas de eucalipto, pode ser dividido em três grandes etapas: (I) Silvicultura, que inicia na produção de mudas de eucalipto para posterior plantio, tratos culturais de manutenção, colheita e transporte da madeira; (II) Fábrica, desde o transporte das toras de eucalipto, sua transformação em polpa celulósica, branqueamento, recuperação e utilidades, estações de tratamento, secagem, dimensionamento e embalagem; e, (III) Distribuição, com transporte do produto final da fábrica até o seu mercado consumidor para a produção de papel e derivados.

$\mathrm{Na}$ Silvicultura, as atividades de preparo e manejo do solo, bem como o plantio das florestas de eucalipto e sua colheita são mecanizados nas grandes empresas do setor. "Pesquisas indicaram que os sistemas silviculturais usam menos combustível e lubrificante para realizar a colheita" (Han et al. 2015 p. 222).

O corte das árvores é do tipo raso e a madeira é descascada e dimensionada ainda na área da colheita. As toras são transportadas por caminhões até o pátio da fábrica. Esta etapa destaca-se pelo potencial de sequestro de carbono durante o crescimento da cultura, quando associada à recuperação e reflorestamento de áreas degradadas, bem como em outros aspectos ambientais por se aplicar a paisagem mosaico no tipo de plantio. Por outro lado, a intensa mecanização da cultura, resulta na combustão de derivados fósseis nas máquinas agrícolas e no transporte, com elevada emissão de dióxido de carbono $\left(\mathrm{CO}_{2}\right)$ para a atmosfera (Gonçalves et al. 2016).

A etapa industrial consiste em curtos e complexos estágios, que inicia no pátio de madeiras com a lavagem e picagem da madeira e encerra no enfardamento da folha de celulose branqueada. A obtenção da pasta celulósica a partir da madeira de eucalipto pode ocorrer por meio de processos industriais diferenciados, sendo, no Brasil, o processo químico Kraft (forte, em alemão) ou Sulfato, o mais utilizado.

O processo Kraft consiste no tratamento dos cavacos em digestores, utilizando-se uma solução de hidróxido de sódio $(\mathrm{NaOH})$, acrescido de sulfeto de sódio $\left(\mathrm{Na}_{2} \mathrm{~S}\right)$, a qual é denominada licor branco. Compõem também a planta 
química, a produção de dióxido de cloro e armazenagem do peróxido de hidrogênio e soda cáustica, insumos utilizados no branqueamento da polpa celulósica.

A etapa industrial é dividida em duas grandes áreas: linha de fibras e planta química. A primeira engloba os processos diretos envolvidos desde o processamento da madeira até a obtenção da folha de celulose branqueada com $90 \%$ seca ao ar.

A planta química constitui a linha de recuperação e utilidades que atua paralelamente a linha de fibras com objetivos diversos. O processo da recuperação química consiste na evaporação, caldeira de recuperação, caustificação e forno de cal. Além disso, tem a função de armazenagem e preparação de enxofre e soda cáustica para reaproveitamento de sódio e enxofre no ciclo da produção. A área de utilidades compõe as estações de tratamento de água (ETA), de efluentes (ETE) e resíduos sólidos ou produção de coprodutos. Além disso realiza a desmineralização de água para as caldeiras, caldeira de biomassa, caldeira a óleo, turbinas e geradores, compressores e distribuição de ar comprimido e distribuição de energia elétrica e vapor para toda a fábrica (Moraes et al. 2014, Silva et al. 2015).

A etapa de Distribuição consiste no transporte do produto final até o consumidor seguinte da cadeia de produção nacional e internacional, ocorrendo por meio terrestre e marítimo a depender da localização e logística definidas (Moraes et al. 2014).

\section{Material e MÉtodos}

A empresa analisada neste estudo localiza-se no estado da Bahia, Brasil, e atua em todas as etapas de produção da celulose branqueada de eucalipto desde a Silvicultura e manufatura da madeira até a entrega dos fardos de celulose ao porto de exportação no estado do Espírito Santo, Brasil. A área do estudo compreende todas estas etapas com ênfase nos processos fabris.

A empresa possui cerca de cem mil hectares de área plantada com eucalipto em diferentes idades. A capacidade produtiva varia em torno de 1 milhão de tonelada de celulose seca ao ar (1 tsa) por ano. Para cada tonelada de celulose produzida são necessários $3,55 \mathrm{~m}^{3}$ de toras de eucalipto.

Uma ACV do tipo "berço ao portão", com dados secundários para a etapa florestal e primário para a etapa industrial e distribuição,foi utilizada para avaliar a pegada de carbono da celulose de eucalipto produzida. O software proprietário Umberto ${ }^{\circledR}$ for Carbon Footprint 1.2 auxiliou no cálculo e análise da pegada de carbono da celulose. Com base nesse software, foram identificados os processos críticos em termos de emissões de GEE passíveis de mitigação e medidas compensatórias. Essa análise do tipo "berço ao portão" também foi utilizada por Garcia and Freire (2014), Han et al (2015) e Silva et al (2015).

O software proprietário Umberto ${ }^{\circledR}$ auxilia o cálculo da pegada de carbono de produto, a partir da modelagem de um fluxograma dos processos do ciclo de vida do produto, com seus respectivos inputs e outputs.

O programa realiza o cálculo, por meio de um fluxo de referência, neste caso o produto principal (fardos de celulose), mensurando a pegada de carbono do ciclo de vida da celulose. O fator de emissão adotado para a fase florestal foi de $15,94 \mathrm{kgCO}-\mathrm{eq} / \mathrm{m}^{3}$, para a tora de eucalipto transportada até o pátio da fábrica, de acordo com a base de dados Ecoinvent 2.2.

A emissão de GEE por unidade de celulose consistirá, portanto, no somatório das emissões ao longo do ciclo de vida, de todos os inputs (fluxos de entrada) e outputs dos processos associados às diferentes etapas do ciclo de vida, considerando as quantidades utilizadas e os respectivos fatores de emissão.

Os princípios da ACV, conforme a ISO 14040/44 (2006) fundamentaram o cálculo e a análise da pegada de carbono. O estudo identificou e quantificou os fluxos de energia e materiais através do Inventário do Ciclo de Vida 
(ICV). O ciclo de vida dos fardos de celulose branqueada foi dividio nas seguintes etapas: a) Etapa I - Silvicultura; b) Etapa II - Fábrica; e, c) Etapa III - Distribuição.

A Etapa I foi modelada com dados secundários (pesquisa bibliográfica, teses, artigos técnicos e científicos e o banco de dados Ecoinvent 2.2). Para as Etapas II e III foi construído um ICV a partir de dados primários extraídos de relatórios anuais da empresa, formulários e planilhas de inventário dos inputs e outputs obtidos em visitas técnicas realizadas à fábrica e, complementados por e-mail e telefone. Adotou-se como unidade de análise uma tonelada de celulose seca ao ar (1 tsa).

A Matriz de Pedigree foi utilizada para estimar as incertezas dos dados do inventário, na qual cada dado é classificado com base em cinco critérios (confiança, integralidade dos dados, correlação temporal, correlação geográfica e correlação tecnológica) e interpretados de acordo com as características qualitativas propostas com pontuações discretas entre 1 a 5. Assim, um conjunto de cinco pontuações dos indicadores é atribuída a cada entrada e saída individualmente (Weidema et al., 2013).

A partir da análise qualitativa obteve-se um vetor pedigree, representado pelas posições de U1 a U5 para cada um dos requisitos citados e a incerteza básica (Ub) para cada categoria de dado. Com o vetor resultado (U1 - U5) calculou-se, conforme indicado em Weidema et al. (2013), a variância utilizando-se a fórmula descrita a seguir:

$S D_{g 95}=\sigma_{g}^{2}=\exp ^{\sqrt{\left[\ln \left(U_{1}\right)\right]^{2}+\left[\ln \left(U_{2}\right)\right]^{2}+\left[\ln \left(U_{3}\right)\right]^{2}+\left[\ln \left(U_{4}\right)\right]^{2}+\left[\ln \left(U_{5}\right)\right]^{2}+\left[\ln \left(U_{6}\right)\right]^{2}+\left[\ln \left(U_{b}\right)\right]^{2}}}$

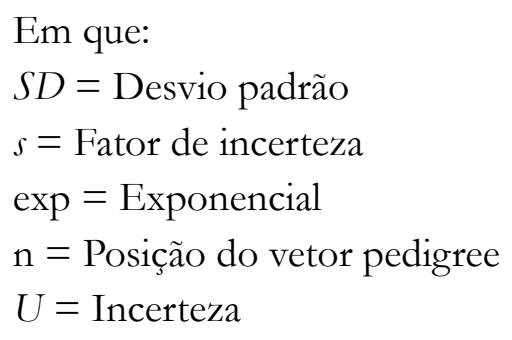

A propagação da incerteza no resultado da pegada de carbono foi estimada utilizando a simulação de Monte Carlo com auxílio de uma planilha eletrônica, com um coeficiente de confiança de 95\% e 1.000 interações.

A análise e interpretação dos dados do inventário foi realizada por meio do estudo do comportamento do modelo, identificando aspectos críticos no ciclo de vida do produto, de um estudo de sensibilidade e da análise de incertezas. Paralelamente, foi realizada uma comparação da pegada de carbono da celulose com dados da literatura e dos relatórios da própria empresa analisada.

Foi apresentado, primeiramente, a distribuição das emissões totais do produto e coprodutos de acordo com a alocação mássica. Posteriormente, foi realizada uma análise de sensibilidade considerando uma alocação econômica das emissões entre produto e coprodutos. As Fórmulas 2 e 3 descrevem como os fatores de alocação econômica oram determinados:

Percentual Produto c: Celulose

$$
\frac{Q c x \$ c}{(Q c x \$ c)+(Q f x \$ f)}
$$

Percentual Produto f: Fibra primária

$$
\frac{Q f x \$ f}{(Q f x \$ f)+(Q c x \$ c)}
$$

Em que:

Q - Quantidade do produto

$\$$ - Valor de mercado 


\section{Resultados E Discussão}

Ciclo de vida da celulose branqueada de encalipto

O ciclo de vida da celulose divide-se em três etapas a saber: I) Silvicultura; II) Indústria; e, III) Distribuição. A Figura 1 apresenta o fluxograma simplificado da silvicultura.

Figura 1. Fluxograma simplificado da Silvicultura.

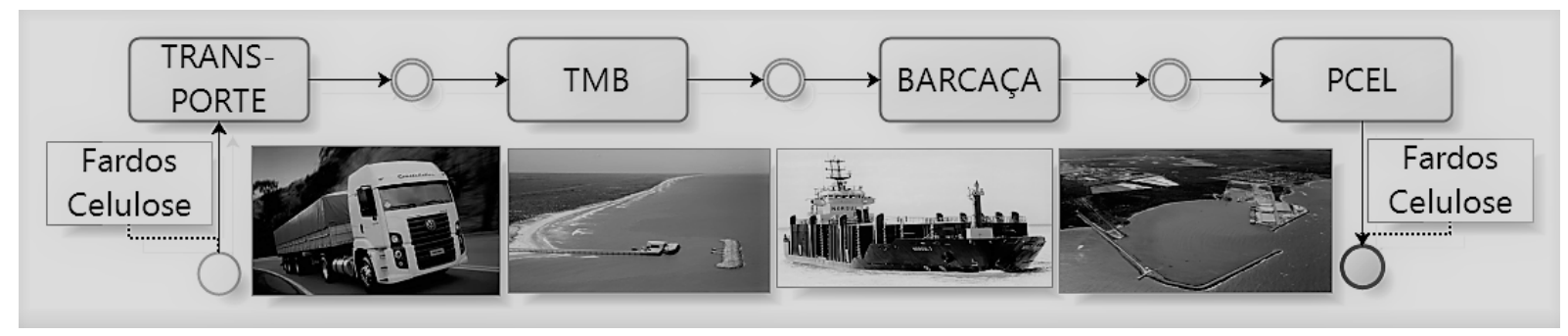

A silvicultura, o processo de produção das mudas de eucalipto é realizado em viveiro próprio com capacidade de até 24 milhões de mudas/ano, onde os plantios são formados 100\% com clones de eucalipto obtidos a partir do cruzamento das espécies Eucalyptus grandis e Eucalyptus urophylla, originárias de regiões de clima tropical.

Nesta etapa, além do uso de combustíveis fósseis oriunda nas atividades de transporte, ocorrem emissões de GEE em função da utilização de máquinas, fertilizantes, corretivos e energia elétrica. Com vistas a mitigar impactos ambientais negativos sobre a biodiversidade e os recursos hídricos, os plantios de eucalipto são realizados em paisagem do tipo mosaico, integrando áreas naturais e de cultivo, de tal modo, a possibilitar a formação de corredores ecológicos e proteção de áreas de mananciais hídricos.

A colheita é realizada, em geral, sete anos após o plantio. O sistema utilizado é o conjunto Harvester e Forwarder ${ }^{1}$. A escolha deste modelo teve como principal razão a retenção no campo da biomassa residual da colheita (cascas, folhas e galhos finos), obtidas durante o corte das árvores e seu dimensionamento em toras, que protegem e melhoram as características físicas e nutricionais do solo.

A etapa industrial (Figura 2) segue o descrito na literatura citada utilizando o processo químico Kraft na produção, o qual consiste no tratamento dos cavacos em digestores com sulfato de sódio e soda cáustica (licor branco). Esta etapa possui duas linhas de produção: a linha de fibras - que se inicia a partir do processamento da madeira, passando pelos processos de cozimento, deslignificação, branqueamento, secagem e se encerra no enfardamento da folha de celulose branqueada, contendo cerca de 10\% de água na composição final - e, a linha de recuperação e utilidades ou, a planta química, que gera energia e reutiliza materiais e insumos que retornam ao ciclo produtivo.

1 A Harvester é um trator derrubador, desgalhador, traçador e empilhador e a Forwarder é um trator florestal, cuja função é realizar o transporte primário por autocarregamento/descarregamento (Linhares et al., 2012). 
Figura 2. Fluxograma da indústria.

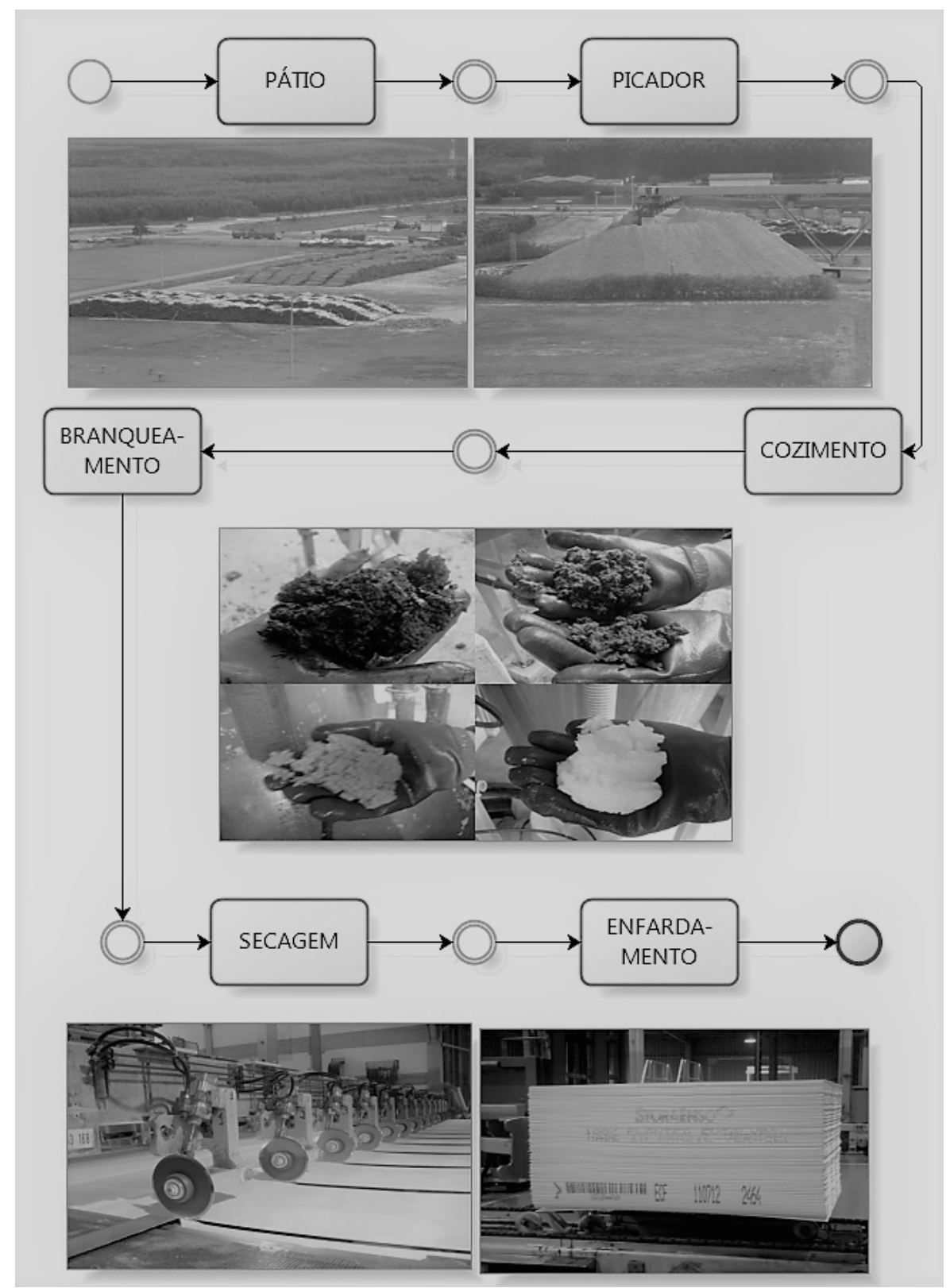

A planta química possui processos complexos de recuperação de químicos essenciais para a produção linear da celulose branqueada. Os principais objetivos são fornecer o licor branco ao digestor após recuperá-lo do cozimento como licor negro (aproximadamente $98 \%$ de recuperação), gerar vapor com a queima do licor negro na caldeira de recuperação e eletricidade no turbogerador, bem como garantir a distribuição de vapor, energia elétrica, água e ar comprimido para a operação da fábrica. Além disso, mantém o tratamento da água, efluentes e resíduos sólidos através das estações de tratamento instaladas na área da empresa.

A Estação de Tratamento de Água (ETA) trata a água bruta captada para uso potável e industrial e está interligada a Estação de Tratamento de Efluentes (ETE) para o caso de transbordo da lagoa pluvial onde a água é reservada. A ETE recebe efluentes industrial, sanitário e geral (água da chuva, águas residuais, etc.) realizando um tratamento biológico a partir de lodos ativados. O efluente tratado retorna ao ambiente natural, enquanto o lodo residuário segue para o tratamento de resíduos sólidos. O tratamento e destinação de resíduos sólidos da empresa ocorre através de uma central com a finalidade de reduzir o descarte de resíduos para o aterro. Os processos de reaproveitamento de material ocorrem por meio de reciclagem, compostagem e/ou reutilização como fertilizantes na agricultura. 
$\mathrm{Na}$ etapa III, de distribuição (Figura 3), o transporte das toras até a fábrica é realizado por meio de uma frota variável de caminhões Siders para carga seca com carrocerias longas com capacidade de 52 toneladas a depender da demanda de produção e distribuição, a qual é disponibilizada e gerenciada por uma empresa terceirizada. A distância percorrida varia devido às diversas áreas de plantio existentes. Uma vez no pátio da fábrica, com o auxílio de empilhadeiras (combustível: gás GLP), as toras seguem para o processamento industrial. Caminhões Siders tipo baú com a mesma capacidade de carga dos anteriores são carregados continuamente com os fardos de celulose, com destino ao terminal marítimo (60 km de distância) gerenciado pela empresa em análise.

Figura 3. Fluxograma da distribuição.

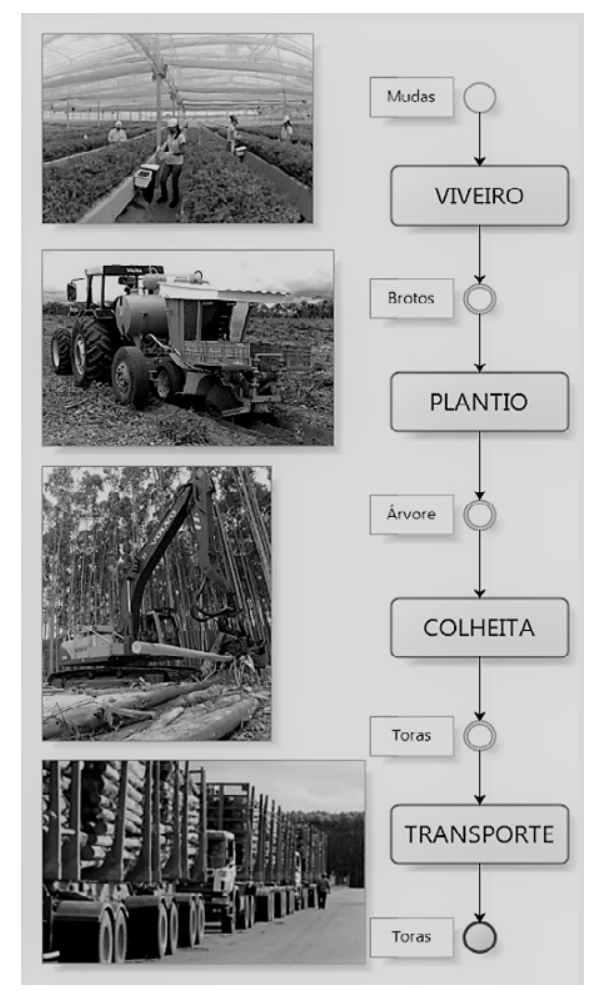

No estudo de Han et al. (2015 p.227) encontrou que "o transporte de toras e biomassa para o mercado é um dos principais contribuintes para os impactos e emissões associadas com a atividade de manejo florestal".

No terminal, seguem por meio de barcaças até o estado do Espírito Santo, a cerca de $530 \mathrm{~km}$ de distância. O Terminal conta com três barcaças e um empurrador. As barcaças são especiais para o carregamento de celulose, possuem motores de proa, apenas utilizados em manobras do tipo bow thruster, sendo necessário que o empurrador esteja acoplado para o seu deslocamento. Além disso, possuem um gerador de bordo para movimentação auxiliar e energia interna. A capacidade de carga para cada barcaça é de 7.122 toneladas de celulose e o carregamento é feito a partir de sete empilhadeiras que carregam $173 \mathrm{t} / \mathrm{h}$.

O empurrador utiliza combustível marítimo óleo MF180 fazendo em média 140 a 142 viagens de ida e vinda por ano com as três barcaças. O ciclo completo (ida e vinda) leva em torno de 54 horas. Ressaltando-se que, na volta, o empurrador retorna com uma barcaça vazia enquanto deixa uma descarregando no estado do Espírito Santo e a terceira carregando no terminal da Bahia. O abastecimento do empurrador ocorre a cada três viagens.

Além da celulose branqueada, o processo de produção gera como coprodutos alguns corretivos de solo $(23,97$ $\mathrm{kg}$ para cada tonelada de celulose), os quais são obtidos a partir da estação de tratamento de resíduos sólidos e fibras primárias $(8,76 \mathrm{~kg}$ para cada tonelada de celulose). Os corretivos de solo são utilizados no plantio do eucalipto, enquanto que a fibra primária é comercializada no mercado interno para fabricação de papel de qualidade inferior. 
Emissões de GEE e pegada de carbono do ciclo de vida da celulose

O montante das emissões de GEE para a produção anual da fábrica estudada foi calculada em 406.652,89 $\mathrm{tCO}_{2}$-eq distribuídos entre as três etapas do ciclo de vida (Tabela 1). A etapa industrial foi apresentada pelos seus principais subprocessos, considerando o elevado número de insumos utilizados. No entanto, uma parte considerável destes insumos apresentou emissões irrelevantes. Logo, a contabilização das emissões por subprocessos, mostrouse uma opção mais adequada.

Tabela 1 - Emissões anuais de GEE da celulose de eucalipto, por input e processo.

\begin{tabular}{|l|l|r|}
\hline \multicolumn{1}{|c|}{ Etapas } & \multicolumn{1}{|c|}{ Inputs / processo } & \multicolumn{1}{c|}{$\begin{array}{c}\text { Emissões } \\
\text { (tCO } \text {-eq) }\end{array}$} \\
\hline I. Silvicultura & Toras de eucalipto & $61.401,82$ \\
\hline \multirow{4}{*}{$\begin{array}{l}\text { II. Indústria } \\
\text { (processos princi- } \\
\text { pais) }\end{array}$} & Pátio & $8.192,23$ \\
\cline { 2 - 3 } & Caldeiras & $2.150,47$ \\
\cline { 2 - 3 } & Linha de fibras & $112.647,74$ \\
\cline { 2 - 3 } & Caustificacão e Forno de cal & $103.021,82$ \\
\cline { 2 - 3 } & Secagem & 913,84 \\
\cline { 2 - 3 } & ETE & $1.263,09$ \\
\cline { 2 - 3 } & ETA & $2.651,00$ \\
\cline { 2 - 3 } III. Distribuição & ETRS & $32.338,63$ \\
\hline & Empilhadeiras & 426,76 \\
\cline { 2 - 3 } & Caminhões & $36.306,07$ \\
\cline { 2 - 3 } & Barcaças & $\mathbf{4 0 6 . 6 5 2 , 8 9}$ \\
\hline
\end{tabular}

A participação das emissões de GEE das diferentes etapas do ciclo de vida da celulose, aponta que a etapa industrial é a responsável pela maior parcela, representando $62,17 \%$.

Os principais inputs responsáveis pela emissão total de GEE no ciclo de vida da celulose foram assim identificados:

- Combustíveis fósseis, representando 47\% das emissões;

- Dióxido de cloro, com 17\%;

- Magnésio, com 8\%

- Hidróxido de sódio, com 7\%

- Outros, $21 \%$

Analisando os inputs industriais individualmente, destacaram-se os quatro com maiores emissões de GEE, representando cada um mais de $10 \%$ do total emitido. São eles:

- Óleo BPF - responsável por 38,23\% do total das emissões fabris dividido em 37,43\% emitido diretamente pela combustão no Forno de Cal e $0,80 \%$ pela caldeira na queima do licor negro para recuperação e produção de energia elétrica através da biomassa de eucalipto;

- Dióxido de cloro - com 25,98\% das emissões industriais indiretas, sendo 25,67\% emitido durante o processo de branqueamento e $0,31 \%$ no tratamento da água;

- Magnésio - responsável por 12,29\% das emissões indiretas industriais durante o processo de tratamento de resíduos;

- Hidróxido de sódio - equivalente a 10,66\% das emissões industriais indiretas, dividido entre os processos da linha de fibras (10,02\%), Estação de Tratamento de Água (0,59\%) e Estação de Tratamento de Efluentes (0,05\%). 
As emissões associadas aos outputs da produção anual da fábrica explicitam o produto e coprodutos obtidos. A Tabela 2 apresenta a produção anual da celulose e seus coprodutos (saídas) e a emissão de cada um referente as Etapas II e III do ciclo de vida da celulose. A análise dos outputs da produção a partir da distribuição das emissões para cada (co)produto evidenciou a participação efetiva do produto principal nas emissões totais do ciclo. Neste caso, os coprodutos obtidos são responsáveis por cerca de 30\% das emissões do ciclo de vida da celulose.

Tabela 2 - Emissões de GEE dos outputs do ciclo de vida da celulose

\begin{tabular}{|l|r|r|}
\hline \multicolumn{1}{|c|}{ Outputs (Produto e Coprodutos) } & Produção (t) & Emissões (tCO -eq) \\
\hline Fardos de celulose (produto principal) & $1.085 .087,00$ & $279.598,95$ \\
\hline Corretivo Humoativo & $3.255,26$ & $8.489,94$ \\
\hline Corretivo Macrocálcio & $3.342,07$ & $20.463,16$ \\
\hline Corretivo Ind. Cinza Calcítica & $6.358,61$ & $38.933,15$ \\
\hline Corretivo Cinza Calcítica & 32,55 & 2,00 \\
\hline Corretivo Cinza Cálcio Mg 38:8 & $5.425,44$ & 33,22 \\
\hline Corretivo Cinza Cálcio Mg & $6.510,52$ & 39,86 \\
\hline Corretivo Humosolo & $1.085,09$ & 847,19 \\
\hline Fibra primárí (lodo primário) & $9.505,36$ & $58.245,42$ \\
\hline Total & - & $\mathbf{4 0 6 . 6 5 2 , 8 9}$ \\
\hline
\end{tabular}

No estudo de Gonzaléz et al. (2011) as emissões de GEE relativas ao consumo de energia elétrica foram as mais significativas, esta diferença para o estudo em tela, pode ser explicada pelas diferenças encontradas entre as matrizes energéticas dos dois países, resultando assim, em diferentes fatores de emissão de GEE para a energia elétrica. De acordo com o Ministério de Desenvolvimento, Indústria e Comércio Exterior (MDIC), mais de 75\% da geração de energia elétrica brasileira é oriunda de usinas hidrelétricas, as quais, são consideradas em sua maioria, de baixa emissão de carbono (Brasil, 2012), enquanto no Chile, a maior parte da geração é realizada por meio de usinas termoelétricas, com maior emissão de GEE por unidade de energia elétrica gerada.

O último relatório publicado pela empresa estudada apontou um resultado cerca de $30 \%$ menor que o obtido nesse estudo $(285,37 \mathrm{~kg} / \mathrm{tsa})$. Isso pode estar relacionado ao fato de que neste estudo foram incluídas etapas do ciclo de vida não consideradas no escopo do referido relatório. Uma das razões evidencia-se pela análise na perspectiva de ciclo de vida, que incluiu todas as entradas e saídas do processo industrial neste estudo, enquanto no relatório da empresa, parte das emissões indiretas, relativas aos insumos utilizados no processo, não foi considerada nos cálculos da pegada de carbono.

O referente relatório apresentou dados de emissão por insumo da atividade industrial apenas para o consumo de calcário dolomítico na caldeira (442,66 tCO $\mathrm{CO}_{2}$-eq). Apesar do óleo BPF, isoladamente representar a maior emissão de gases estufa da etapa industrial, esta pesquisa apontou o processo de Linha de Fibras, como o subprocesso de maior emissão, em especial pela emissão indireta associada ao consumo do dióxido de cloro na etapa de branqueamento da polpa de celulose.

Esta constatação aponta para a relevância do estudo de alternativas de mitigação para estas emissões. A substituição do GLP utilizado nas empilhadeiras (responsáveis por apenas 1\% das emissões do ciclo), por biodiesel, pode reduzir as emissões nos processos em que são utilizadas. Sabe-se, contudo, que a produção do biodiesel pode também gerar emissões significativas de GEE em seu ciclo vida, dependendo da matéria-prima e do processo tecnológico utilizado. Logo, a substituição deve ser precedida de estudos de viabilidade ambiental, apresentando o balanço final das emissões/sequestro.

Outra etapa crítica do ciclo de vida refere-se ao processo de branqueamento da polpa de celulose, no qual o consumo de dióxido de cloro $(9,98 \mathrm{~kg} / \mathrm{tsa})$ se destaca como o responsável pela segunda maior emissão indireta de GEE no ciclo vida da celulose. O fator de emissão deste insumo, de acordo com o banco de dados Ecoinvent 2.2, é de 6,24 kgCO 2 -eq. Em comparação com outros insumos utilizados na produção da celulose, o dióxido de cloro 
possui o maior fator de emissão por unidade de massa. Comparativamente, o hidróxido de sódio, por exemplo, consumido em maior quantidade durante o branqueamento (cerca de $30 \mathrm{~kg} / \mathrm{tsa}$ ), possui um fator de emissão de aproximadamente 6 vezes menor, de $1,10 \mathrm{kgCO}-$-eq $/ \mathrm{kg}$ de produto.

Um terceiro aspecto crítico do ciclo de vida da celulose foi encontrado no consumo de magnésio durante os processos de tratamento de resíduos sólidos, para a produção de corretivos de acidez do solo. O magnésio possui um fator de emissão de $73,76 \mathrm{kgCO}_{2}$-eq $/ \mathrm{kg}$ (Ecoinvent 2.2) portanto, mesmo consumido em pequena escala $(0,4$ $\mathrm{kg} / \mathrm{tsa}$ ), sua emissão total foi equivalente a cerca de $50 \%$ da emissão do dióxido de cloro no branqueamento.

Assim como o dióxido de cloro, o magnésio também não foi computado nas emissões inventariadas pela empresa, publicadas no relatório de sustentabilidade. Seu consumo ocorre dentro de uma organização que foi terceirizada, e atua em operação dentro do território da fábrica estudada, sendo responsável pelo tratamento dos resíduos sólidos e pelo aterro industrial ${ }^{2}$.

Os resultados destacaram o hidróxido de sódio como o quarto maior emissor de gases estufa no ciclo de vida da celulose. Seu consumo ocorre em três processos diferentes (Linha de fibras, ETE e ETA), sendo que na Linha fibras, mais especificamente no cozimento dos cavacos de eucalipto no digestor e no branqueamento, que seu consumo é relevante (mais de $99 \%$ do total).

Vale ressaltar, todavia, como fatores positivos da produção, que a fábrica reutiliza mais de $90 \%$ dos seus resíduos sólidos por meio da estação de tratamento, produzindo adubos e corretivos de solo. O chorume gerado pelo aterro sanitário também é reutilizado pela fábrica em seus processos de tratamento dos efluentes gerais. Com relação ao consumo de energia elétrica, a fábrica gera sua própria energia a partir do aproveitamento dos coprodutos biomassa residual de eucalipto e licor negro gerado no cozimento, oriundos da Etapa II. O processo de recuperação química, que paralelo à produção de fibras, além de gerar e distribuir energia suficiente para toda a planta da empresa, recupera insumos que retornam ao processo, como o próprio licor negro.

O trabalho de Han et al. (2015) e Silva et al. (2015) também indicam o aproveitamento dos produtos residuais para a geração de energia, bem como os trabalhos apresentados por Gonzalez et al. (2011) e Silva et al. (2015).

A fábrica apresenta oportunidades de mitigação da sua pegada de carbono, por meio de créditos de carbono comercializados no mercado internacional, a partir de investimentos em medidas ambientais, como projetos dentro do Mecanismo de Desenvolvimento Limpo (MDL), visando obter compensações ambientais, lucros econômicos e agregar um diferencial competitivo ao seu produto para exportação. Dentro desta perspectiva, a empresa em tela, estuda um projeto de MDL, com o objetivo de substituir parte do seu consumo de diesel fóssil, por biodiesel produzido a partir do óleo extraído das sementes de pinhão-manso (Jathropa curcas).

\section{ConClusões}

O uso de combustíveis fósseis nas caldeiras e de dióxido de cloro, hidróxido de sódio e magnésio na etapa I do processo de produção industrial foram os maiores responsáveis pelas emissões de GEE no ciclo de vida da celulose eucalipto, sendo o consumo de combustíveis fósseis o mais relevante individualmente. Neste aspecto, este estudo corrobora com a tendência de que a combustão de recursos fósseis é o principal fator para o aumento da concentração de GEE na atmosfera, e consequentemente para o aquecimento global.

A implantação e execução de um MDL para substituir o combustível fóssil por um biocombustível pode trazer benefícios ambientais e econômicos para empresa, além de favorecer a sua imagem perante o mercado consumidor, em especial o europeu. No entanto, deve-se atentar para os impactos ambientais negativos no ciclo de vida dos biocombustíveis. Um estudo de ACV para as alternativas aos combustíveis fósseis na implantação do MDL é uma das formas a serem consideradas para analisar as melhores alternativas.

2 Aterro sanitário Classe II (não-inerte) classificado de acordo a ABNT NBR 10.004:2004, norma da Associação Brasileira de Normas Técnicas, que trata da Classificação de resíduos, (ABNT, 2004). 
A perspectiva após este estudo é de que outras pesquisas sejam realizadas, principalmente, quanto ao cultivo do eucalipto para investigar as possibilidades de sequestro e mitigação das emissões de GEE, visando a obtenção de dados que possibilitem a obtenção de um inventário do ciclo de vida com dados primários desta etapa.

A alocação econômica mostrou-se ser a mais indicada, considerando se tratar de uma commodity e possibilitar uma integração com as análises econômicas por parte da empresa, do setor de celulose e de estudiosos da área de produção de celulose.

Frente a tendência de crescimento na demanda mundial por celulose, destaca-se a importância de dedicar especial atenção aos aspectos críticos relacionados às entradas e saídas com relação às emissões de GEE, bem como, às possibilidades para mitigação da pegada de carbono, considerando o potencial das novas tecnologias para a substituição de insumos e da perspectiva da integração de processos industriais, visando a valorização de coprodutos e resíduos e minimização das emissões de GEE por unidade de celulose de eucalipto.

\section{Agradecimentos}

À Universidade Estadual de Santa Cruz (UESC) pela infraestrutura e tecnologia, ao Programa de PósGraduação em Desenvolvimento e Meio Ambiente da UESC e ao grupo Bioenergia e Meio Ambiente (BioMA) pelo apoio.

\section{REFERÊNCIAS}

ABNT (Associação Brasileira de Normas Técnicas). NBR 10.004:2004. Resíduos sólidos: classificação. São Paulo: ABNT, 2004.

Almeida F. 2007. Os desafios da sustentabilidade: uma ruptura urgente. 3 ed. Rio de Janeiro: Elsevier.

BPWG. 2010. Biobased Products Working Group. Principles for the accounting of biogenic carbon in product carbon footprint standards. In: Biotechnology Industry Organization.

BRASIL. 2012. Matriz energética brasileira tem 88,8\% de geração de fontes renováveis. Disponível em: http:/ /www.brasil. gov.br/infraestrutura/2012/06/matriz-energetica-brasileira-tem-88-8-de-geracao-de-fontes-renovaveis. Acesso em: 19 Dez. 2014.

BSI. 2008. PAS 2050:2008. Specification for the Assessment of the Life Cycle Greenhouse Gas Emissions of Goods and Services. British Standards Institution, London.

BSI. 2011. PAS 2050:2011. Specification for the Assessment of the Life Cycle Greenhouse Gas Emissions of Goods and Services. British Standards Institution, London.

CARBON Trust. 2006. Carbon footprints in the supply chain: the next step for business. Report Number CTC616, Nov. The Carbon Trust. London, UK. Disponível em: http://www.carbontrust.co.uk Acesso em 12 Apr. 2014.

Garcia R. e Freire F. 2014. Carbon footprint of particleboard: a comparison between ISO/TS 14067, GHG Protocol, PAS 2050 and Climate Declaration. In: Journal of Cleaner Production. 66, pp 199-209.

Gonçalves CF, Gouveia ES, Rodrigues LB e Almeida Neto JA. 2016. Inventário do Ciclo de Vida do eucalipto para a produção de celulose na Bahia. In: Anais... V Congresso Brasileiro de Gestão do Ciclo de Vida. Fortaleza: VCBGCV. 
Gonzalez P, Vega M. e Zaror C. 2011. Life cycle inventory of pine and eucalyptus cellulose production in Chile: effect of process modifications. (ed.) M. Finkbeiner Towards Life Cycle Sustainability Management. DOI 10.1007/978-94-0071899-9_25.

Han HS, Oneil E, Bergman RD, Eastin IL e Johnson LR. 2015. Cradle-to-gate life cycle impacts of redwood forest resource harvesting in northern California. In: Journal of Cleaner Production. 99, pp. 217-229.

Heiskanen, E. 2002. The institutional logic of life cycle thinking. In: Journal of Cleaner Production. 10, pp. 427-437.

IEC. 2008. General Programme Instructions for Environmental Product Declarations. Disponível em: http://www. environdec.com/en/The-EPD-system/Programme-Instructions/ Acesso em 20 Abr. 12.

IPCC. 2014. Intergovernmental Panel Climate Change: Working Group III. Climate Change 2014: Mitigation of Climate Change.

ISO (International Organization for Standardization). 2006. Environmental management - Life cycle assessment - Principles and framework. ISO 14040. Genebra, Suiça: ISO. 2015.

ISO/TS,.2013. ISO/TS 14067: Greenhouse Gases e Carbon Footprint of Products e Requirements and Guidelines for Quantification and Communication (Technical Specifications). International Organization for Standardization, Geneve.

Linhares M, Sette Jr. CR, Campos F e Yamaji FM. 2012. Eficiência e desempenho operacional de máquinas Harvester e Forwarder na colheita florestal. Pesqui. Agropecu. Trop. [online]. Vol.42, n.2, pp. 212-219.

Lovelock J. 2010. Gaia: Alerta final. Rio de Janeiro: Intríseca, 2010.

Martins G, Carso NM, Kureski R, Hosokawa RT e Rochadelli R. 2003. Inserção do setor florestal na estrutura econômica do Paraná. Rev. Paranaense Desenvolvimento, n.104, pp. 5-21, Jan./Jun.

Miller Jr GT. 2008. Ciência Ambiental. Eleventh ed. São Paulo: Cengage Learning.

Moraes FAB, Piratelli CL e Achcar JA. 2014. Condições ideais para o consumo específico de madeira na produção de celulose. Production, v.24, n.3, pp.712-24, Jul./Set.

Pinheiro H, Castro JPM e Azevedo JC. 2014. Alterações na paisagem e sequestro de carbono na freguesia de Deilão, nordeste de Portugal. Revista Árvore, Viçosa-MG-Brasil, v.38, n.1, pp.41-52.

SETAC. 2009. Life Cycle Initiative. Society of Environmental Toxicology and Chemistry. Life Cycle Management. How business uses it to decrease footprint, create opportunities and make value chains more sustainable. UNEP.

Silva DAL, Pavan ALR, Oliveira JA, Ometto AR. 2015. Life cycle assessment of offset paper production in Brazil: hotspots and cleaner production alternatives. In: Journal of Cleaner Production 93. p. 222-233.

Sousa EP, Soares NS, Silva ML e Valverde SR. 2010. Desempenho do setor florestal para a economia brasileira: uma abordagem da Matriz Insumo-Produto. Revista Árvore, vol.34 n.6, Viçosa Nov./Dez.

Soares NS, Silva ML e Cordeiro SA. 2014. Produto interno bruto do setor florestal brasileiro, 1994 a 2008. Rev. Árvore [online]. vol.38, n.4, pp. 725-732. 
Torres CMME, Jacovine LAG, Soares CPB, Oliveira Neto SN, Santos RD e Castro Neto F. 2013. Quantificação de biomassa e estocagem de carbono em uma floresta estacional semidecidual, no Parque Tecnológico de Viçosa, G. Rev. Árvore [online] vol.37, n.4, pp. 647-655.

Valverde SR, Oliveira GG, Carvalho RMAM e Soares TS. 2005. Efeitos multiplicadores do setor florestal na economia capixaba. Revista Árvore, v.29, n.1, pp. 85-93.

Weidema BP, Bauer C, Hischier R, Mutel C, Nemecek T, Reinhard J, Vadenbo CO e Wernet G. 2013. Overview and methodology. Data quality guideline for the ecoinvent database version 3. Ecoinvent report data v. 3. St. Gallen: The ecoinvent Centre, n. 1.

Wackernagel M. e Rees W. 1996. Our Ecological Footprint: Reducing Human Impact on the Earth. Philadelphia, PA: New Society Publishers, pp. 160. 